\title{
Influence of aversive visual stimulation on attention, working memory, and anxiety in university students
}

\author{
Paulo Ricardo Giron and Rosa Maria Martins de Almeida \\ Universidade do Vale do Rio dos Sinos, Brazil
}

\begin{abstract}
The present study investigated the influence of aversive visual stimulation on anxiety, working memory, and selective attention. The study was conducted with 366 participants of both sexes, divided into three groups: $(i)$ no visual stimuli $(n=128)$, (ii) neutral visual stimuli $(n=114)$, and (iii) aversive visual stimuli $(n=124)$. Two DVD films, one containing aversive stimuli and one containing neutral stimuli, were used for the respective groups. Each visual stimulation had a duration of 1 minute and 22 seconds. After viewing the DVD, anxiety, working memory, and attention were assessed. Concomitant with the increase in anxiety were deficits in working memory and deficits in selective attention in the group that was exposed to the aversive scenes. No gender differences were observed. These results suggest that aversive visual stimuli increase anxiety and decrease attention and working memory performance in university students. Keywords: gender, mood induction, emotion, cognition.
\end{abstract}

Received 15 October 2009; received in revised form 9 February 2010; accepted 9 February 2010. Available on line 25 June 2010.

\section{Introduction}

Studies on violence have been increasing, but not in the same proportion as the actual rise in violence, which has afflicted society and caused cognitive damage (McAlister, 2000; Rangel, 2004a).

Progress in the means of communication, the greater speed and quantity of information acquired, and the relationship between human perception and behavioral support underscore the importance of studying the fields of communication, cognition, and social relationships to better understand basic processes (Aronson, 1995; Rangel, 2004a).

Visual exposure to violence on television and its effects on aggressive behavior in children and adults have been increasingly explored since the 1980 s, when the strong correlation between this type of stimulus and the rise in aggressive behavior was established (Centerwall, 1989; Gerbner, 1988). This fact was

Paulo Ricardo Giron, Programa de Pós-Graduação em Psicologia Clínica da Universidade do Vale do Rio dos Sinos-UNISINOS, Brazil. Rosa Maria Martins de Almeida, Instituto de Psicologia do Desenvolvimento e da Personalidade da Universidade Federal do Rio Grande do Sul (UFRGS), Laboratório de Psicologia Experimental, Neurociências e Comportamento, Porto Alegre, RS, Brazil. Correspondence regarding this article should be directed to: Rosa Maria Martins de Almeida, Instituto de Psicologia - UFRGS Rua Ramiro Barcelos, 2600 - Bairro Santa Cecília Porto Alegre - RS - Brazil CEP 90035-003 - Fone: (51) 3308-5066 - Fax: (51) 3308-5470 e-mail: rosa_almeida@yahoo.com or rosa.almeida@ufrgs.br noted in the report of the Surgeon General's Scientific Advisory Committee on Television and Social Behavior (1972) and the National Commission on the Causes and Prevention of Violence (Gerbner, 1988), which concluded that the increase in violence is directly associated with the increase in violence in the media, which was subsequently confirmed by the National Institute of Mental Health (Rangel, 2004b).

According to some studies (Aluja-Fabregat \& Torrubia-Beltri, 1998; Comstock \& Strasburger, 1990; Freedman, 1984), this visually witnessed violence, especially on television, stimulates aggressive behavior. The concern raised by these authors is based on the fact that this observed violence covers all violent acts witnessed by the individual. Even if the individual is not directly involved in the action, the person could be subject to suffering only by viewing it. The consequences of this type of visual stimulation are not yet fully known. Normally these types of stimuli, either active or passive, affect the spectator (Browne \& Hamilton-Giachritsis, 2005). This stimulation has been termed "life events" to emphasize that they are common in our daily lives and in most cases are not noticed. The stressful stimulation was also classified as either dependent (i.e., with action and participation of the individual) or independent (i.e., without the individual being a participant or directly affecting the event; Margis, Picon, Cosner, \& Silveira, 2003).

The influence of daily stressful stimuli on child behavior was verified by Gerbner (1988), which showed that children suffer the most or endure the most cognitive changes from this exposure (Anderson, 
2004; Bar-on et al., 2001; Bensley \& Van Eenwyk, 2001; Bushman \& Cantor, 2003; Cantor, 2000; Cook, Kestenbaum, Honaker, \& Anderson, 2000; Groebel, 1998; Gunter \& Furnham, 1984; Huesmann, MoiseTitus, Podolski, \& Eron, 2003; Kirsh, 2003; Nathanson \& Cantor, 2000; Sargent et al., 2002; Sherry, 2001; Vooijs \& van der Voort, 1993).

With the advent of the Internet, visual stimuli generated by electronic images, such as computer and television, also have an important role in cognition and the emotional state of the spectator because of increased exposure. Browne and Hamilton-Giachritsis (2005) suggested the urgent need to understand the short- and long-term effects of visual stimuli through these types of technology, such as virtual reality.

Studies have shown alterations caused by immediate stress of individuals facing adverse situations, but little is known about their subsequent effects related to the subject's daily life, at least with regard to mental function, such as concentrated attention and working memory.

The majority of the few extant studies relate to diagnosis, in which the main objective is to observe symptoms of certain diseases, such as anxiety disorders (Graeff, 1999; Ribeiro \& Kapczinski, 2000). Other research follows this line of study by investigating the mental damage caused by stressful stimuli, which are more durable, when adverse or stressful stimuli are not present.

At some point in the life of the individual, adverse stimuli can generate trauma, such as posttraumatic stress disorder, caused by a stressful event or a moment of intense adverse stimulation (Katz, Fleisher, Kjernisted, \& Milanese, 1996; Yehuda \& Davidson, 2000). Stressful events include any stimulus load that alters the body's homeostasis, causing it to react to re-establish balance (Silberg, Rutter, Neale, \& Eaves, 2001). Using this definition, some authors have investigated adverse stimuli and their relationship to changes in behavior and well-being by researching relationships between the stimuli and anxiety (Cano \& O'Leary, 2000; Kendler, Karkowski, \& Prescott, 1999; Silberg et al., 2001).

Violence depicted in daily events involves adverse exciting stimuli that generate changes in behavior. Aronson (1995) suggested the "potential danger" of visual adverse stimuli present in television media. Additionally, Heilman (1997) first made the distinction of emotion, referring to it as emotional valence and classifying it in negative or positive terms according to the affection generated (i.e., avoidance or approximation, respectively) to further make observations of the influence of stimuli on the response of individuals and to map brain images.

Importantly, adverse stimuli are those that cause anxiety, particularly feelings of revulsion, which are different from stimuli that also trigger anxiety by pleasurable feelings. Ritz, Alatupa, Thoms and Dahme (2002) explored the effect of pleasant visual stimuli on asthma symptoms. Even without the term "emotional valence," Ritz et al. (2002) found that adverse and pleasurable stimuli impacted symptomatology and could be classified as stressful stimuli in asthma. Therefore, the state of anxiety appears to affect the valence of a certain stimulus, both pleasurable and adverse. According to Labrador and Crespo (1993), the stress causes anxiety through stimuli perception that causes emotional excitement to upset homeostasis and trigger an adaptational process. This state generates other alterations, such as increased secretion of epinephrine, which produces systemic manifestations, including physiological and psychological disorders. Therefore, the state of anxiety can be found with both adverse and pleasurable stimulation. According to Margis et al. (2003), important changes in life, such as starting a new job, can generate a stress response in individuals, and this response can interfere with mental processes as much as suffering from an accident.

The literature has demonstrated possible interference from a wide range of stimulation in our daily lives, although studies that have analyzed residual changes caused by adverse stimuli, such as short-term memory ability and concentrated attention, are practically nonexistent. Moreover, little research has used uncommitted populations that do not have any diagnosis, which is why further investigations are necessary. Therefore, considering the large amount of visual adverse stimulation (unpleasant emotion) encountered during people's daily lives and the paucity of research on the subject, investigating the effects of stressful stimuli is necessary to better understand cognition and human beings' performance in their daily lives.

Further scientific research is necessary concerning adverse visual stimuli (unpleasant emotions) to understand whether they can produce changes in the capacity of concentrated attention and working memory. Thus, the goals of the present study were to determine whether adverse visual stimuli are able to alter working memory and selective attention and whether anxiety plays an important role in this process.

\section{Method}

This research was quantitatively transverse because of the analysis and data collection procedures. The study is experimental and conclusive as to its purpose, with the objective of responding to the hypotheses with experimental character (control group).

\section{Participants}

This study included a total of 366 participants of both sexes, aged 18 and 52 years, averaging 24 years and 4 months $(S D=4.96)$. Subjects were divided into 
Table 1. Description of the groups and percentage (\%) of females and males in each group and total number $(n)$ of participants.

\begin{tabular}{|c|c|c|c|c|c|c|}
\hline \multirow{3}{*}{ Group } & \multicolumn{4}{|c|}{ Sex } & \multirow{2}{*}{\multicolumn{2}{|c|}{ Total }} \\
\hline & \multicolumn{2}{|c|}{ Female } & \multicolumn{2}{|c|}{ Male } & & \\
\hline & $n$ & $\%$ & $n$ & $\%$ & $n$ & $\%$ \\
\hline Control & 68 & $54 \%$ & 60 & $46 \%$ & 128 & $35 \%$ \\
\hline Neutral Stimuli & 60 & $52 \%$ & 54 & $48 \%$ & 114 & $31 \%$ \\
\hline Aversive Stimuli & 71 & $57 \%$ & 53 & $43 \%$ & 124 & $34 \%$ \\
\hline Total & 199 & $54 \%$ & 167 & $46 \%$ & 128 & $35 \%$ \\
\hline
\end{tabular}

three groups: $(i)$ no visual stimulation $(n=128)$, $(i i)$ neutral visual stimulation $(n=114)$, and $($ iii $)$ adverse visual stimulation $(n=124)$ (Table 1$)$.

In Group 1 (no visual stimuli [no movie]), 54\% of 128 participants were female $(n=68)$ and $46 \%$ were male $(n=60)$. An average of 25 students per session (i.e., one class) completed the questionnaire. In Group 2 (neutral visual stimulation), $52 \%$ of 114 participants were female $(n=60)$ and $48 \%$ were male $(n=54)$. In Group 3 (adverse stimulation), 57\% of 124 participants were female $(n=71)$ and $43 \%$ were male $(n=53)$.

The highest family income of the sample consisted of $38.25 \%(n=140)$ with an income between $\mathrm{R} \$ 3,000.00$ and $\mathrm{R} \$ 1,001.00$. Most of the sample was between the second and fourth semester (79.23\%) of their courses. The average time spent at university was 3.2 semesters $(S D=.70)$. A questionnaire was used that included a total of five direct questions about visual stimulation through movies, in addition to demographic identification and a self-assessment test regarding emotional valence experienced by movies. Two DVD movies, one including the contents of a hit-and-run accident (adverse) and another including neutral content (a person running continuously without his face being shown), were used for the respective groups. Each visual stimulation had duration of 1 minute and 22 seconds.

\section{Instruments}

The three selected tests to compose the battery of this study were the following:

State-Trait Anxiety Inventory (STAXI): This instrument was created by Spielberger, Gorsuch and Lushene (1970), translated, and adapted to Brazil by Biaggio and Natalício (1979/2004). The STAXI presents anxiety scales divided into statetrait, rendering the class of anxiety identifiable (i.e., situational [provoked or momentary] or trait [more permanent]). The STAXI also presents standards for these two factors, as well as for the entire scale (single factor with 20 items; Cronbach $\alpha=.79$ ), and allows for distinctions between males and females.
Concentrated Attention (CA): This instrument was produced by Cambraia (1967) to identify the level of attention and it has reliability (Cronbach $\alpha=.73$ ).

Personal Selection Testing subtest for memory (PST-M): This instrument was created by King (2004). The PST-M is composed of 11 subtests, presenting scores for attention, perception, thought, dexterity, memory, dimension, parts, precision, fluency, objects, and judgment among others. The memory test was employed in this research to account for visual exercise performed in daily life. The PST-M scores the ability to retain and mention names, traits, and details.

A pilot study was carried out with 23 students of both sexes to examine the structure of the questionnaire and emotional valence of the content of visual stimulation (movies). The content of the movies was suitable for what was proposed, considering that the movie with adverse content (visual stimulation with unpleasant emotions) was identified as adverse and unpleasant by $100 \%$ of the participants, and the neutral movie was identified as "normal" by $75 \%$ of the participants (with classifications of "pleasant" and "curious" by the other $25 \%$ ).

The study began by recruiting participants from classes of each department of a private university in the metropolitan area of Porto Alegre. Subsequently, recruitment from classes that would represent each department was carried out (Departments of Exact, Human, Law, Social Communication and Economic Sciences and Department of Health) so that each department contributed three classes. Each class was assigned to a specific group (Group 1, 2, or 3). The first class comprised Group 1 (control group), the second class comprised Group 2 (neutral visual stimulation), and the third class comprised Group 3 (adverse visual stimulation [unpleasant emotions]). After the purpose of the study was explained, the three groups completed the consent form.

\section{Procedure}

The procedures of the three groups were identical, with the only difference that after the consent form was 
collected, testing of Group 1 began without playing the short movie. Group 1 (no visual stimuli [no film]) was composed of 133 students, with an average of 25 students participating at one time (one class) to answer the questionnaire. For Group 2 (neutral visual stimulation), the initial procedure was identical to Group 1, but after completing the consent form, the movie with repetitive visual stimuli was shown. The movie duration was 1 minute and 22 seconds, in which a person appeared on the screen with the back turned to the audience (i.e., the face was never shown), running along a deserted road. After the movie, participants answered a questionnaire, and tests (anxiety, attention, and memory) were administered. The order of the tests was changed to avoid the same order of instrument application. In Group 3 (adverse visual stimuli), the same procedure as Group 2 was used, but the film showed scenes of a hit-and-run accident. The total time of visual exposure to the film was 1 minute and 22 seconds. Films were previously edited to have the same duration. The STAXI lasted 10 minutes. The AC test lasted 5 minutes, and the PST-M lasted 30 minutes. The total time for application of all tests was 45 minutes.

Data were analyzed using SPSS software for Windows version 17.0. Analysis of variance (ANOVA) was used to analyze the variables of the three groups. Student's $t$-test was used to analyze gender differences, and the Bonferroni post hoc test was used to analyze the relationships between variables. Values of $p<.05$ were considered statistically significant (Table 2 ).

\section{Results}

The results showed that the groups subjected to adverse stimulation had changes in working memory (PST-M) and attention (AC), with significantly reduced performance and elevated anxiety scores (STAXI). A significant increase in the level of anxiety in the group with adverse stimulation was also found when compared with the control and neutral groups. The questionnaire also showed the grading of the movie watched by the participants. In Group 2, 87\% of the sample classified the movie as neutral. In Group 3, $88.7 \%$ of the sample classified the movie as adverse. When asked about the frequency of unpleasant events in daily life, $54.64 \%(n=$ 200) of the participants responded that such unpleasant events occur a few times per month. Subsequently, participants were asked to define what would be adverse and what each participant would avoid witnessing or watching. More than $80 \%$ of the entire sample indicated dramatic events such as fire, assault, and death. Only $12.29 \%$ would avoid an adverse movie. Finally, the last part of the questionnaire investigated how participants judged their memory, and more than $60 \%$ of the total sample was satisfied with their memory, believing it as good or great. Comparisons of the anxiety variable of the three groups indicated a significant difference between Group 3 (adverse stimulation) and the other groups. Group 1 (control) had $M=42.41$ and $S D=$ 7.8. Group 2 (neutral) had $M=42.71$ and $S D=7.53$. Group 3 (adverse visual stimulation) had $M=52.72$ and $S D=10.08$ (Figure 1). The attention variable was also different between Group 3 (adverse stimulation) and the other groups. Group 1 (control) had $M=93.76$ and $S D=$ 17.05. Group 2 (neutral visual stimulation) had $M=91.15$ and $S D=14.96$. Group 3 (adverse visual stimulation) had $M=74.25$ and $S D=11.43$ (Figure 2). With regard to the working memory variable, a significant difference was found between Group 3 (adverse stimulation) and the other two groups. Group 1 (control) had $M=38.27$ and $S D=7.46$. Group 2 (neutral visual stimulation) had $M=37.43$ and $S D=6.87$. Group 3 (adverse visual stimulation) had $M=28.22$ and $S D=7.18$ (Figure 3).

\section{Discussion}

Students presented high levels of anxiety when subjected to aversive visual stimulation (aversive film) and a decline in their working memory and concentrated attention compared with the participants of the other

Table 2. Anxiety, working memory, and attention scores from each group (mean $[M]$ and standard deviation $[S D]$.

\begin{tabular}{|c|c|c|c|c|c|c|c|}
\hline \multirow{3}{*}{ Test } & \multicolumn{6}{|c|}{ Group } & \multirow{3}{*}{$F(d f)$} \\
\hline & \multicolumn{2}{|c|}{ G1 } & \multicolumn{2}{|c|}{ G2 } & \multicolumn{2}{|c|}{ G3 } & \\
\hline & $M$ & $S D$ & $M$ & $S D$ & $M$ & $S D$ & \\
\hline Anxiety & 42.41 & 7.80 & 42.71 & 7.53 & 52.71 & 10.08 & $59.09(2)^{* * *}$ \\
\hline Working Memory & 38.27 & 7.46 & 37.43 & 6.87 & 28.22 & 7.18 & $74.40(2)^{* * *}$ \\
\hline Attention & 93.76 & 17.07 & 91.15 & 14.96 & 74.25 & 11.43 & $51.52(2)^{* * *}$ \\
\hline
\end{tabular}

$* p<.05, * * p<.01, * * * p<.001$

*** significantly different from control and neutral groups 


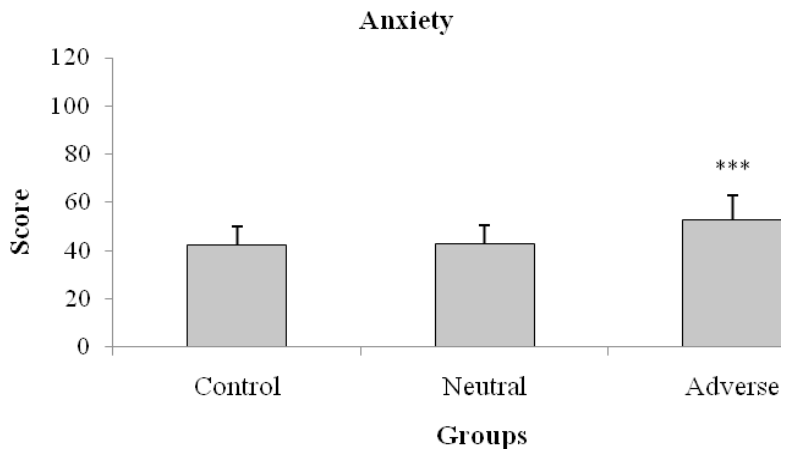

Figure 1. Anxiety level scores from the three groups. G1, Group 1 (control); G2, Group 2 (neutral visual stimulation); G3, Group 3 (adverse visual stimulation). $* * * p<.001$.

*** significantly different from control and neutral groups

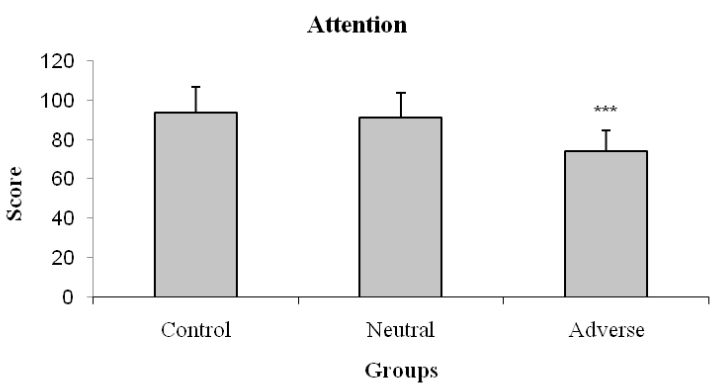

Figure 2. Attention scores from the three groups. G1, Group 1 (control); G2, Group 2 (neutral visual stimulation); G3, Group 3 (adverse visual stimulation). $* * * p<.001$.

*** significantly different from control and neutral groups

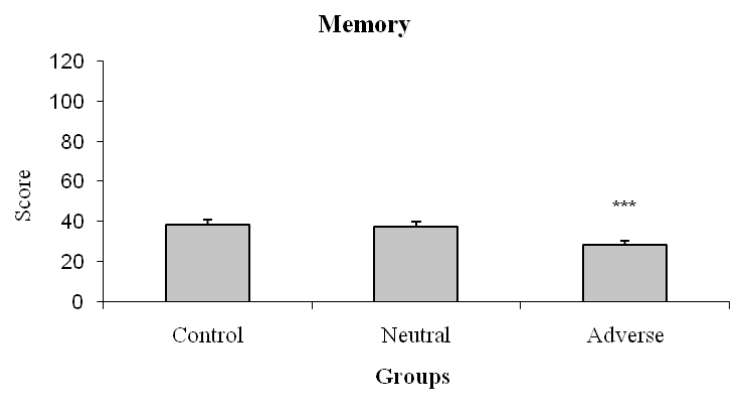

Figure 3. Working memory scores from the three groups. G1, Group 1 (control); G2, Group 2 (neutral visual stimulation); G3, Group 3 (adverse visual stimulation). ${ }^{* * *} p<.001$. $* * *$ significantly different from control and neutral groups

groups without the same stimulation. No significant differences in outcome were observed between males and females in both questionnaire responses and tests. Cognitive function analyzed after aversive stimulation suffered similarly in males and females. Previous studies have demonstrated differences in brain activation, under the same conditions, of a sample of women compared with men, but generally, the functions of working memory and concentrated attention show the same performance (Sarlani \& Greenspan, 2002;
Schneider, 2000; Shields, 2003; Zald \& Kim, 1998). Other authors have shown that men and women tend to present differences when judgment, logic, and verbal expression are analyzed (Gorsky \& Willis, 2003; Gur, Gunning-Dixon, Bilker, \& Gur, 2002). Differences may exist between performance in both sexes, depending on the combination of stimulation and the function analyzed. Working memory and concentrated attention performance declined when participants were subjected to a state of anxiety caused by aversive stimulation, while the performance of the other groups remained unchanged. These data indicate a relationship between anxiety and performance in concentrated attention and short-term memory.

Anxiety is known to play an important role in the functions of memory, learning, decision-making, and creativity (Compton, 2003; Damasio, 1999; Davis \& Whalen, 2001; Dolan, 2002; Loewenstein \& Lerner, 2003). Mental function performance is directly linked to the different levels of anxiety experienced and the strategies adopted by each individual to deal with this function (Gable, Reis, \& Elliot, 2000; Leen-Feldner et al., 2007; Sloan \& Kornstein, 2003; Updegraff, Gable, $\&$ Taylor, 2004). Aversive stimulation in the induction of humor (Gilet 2008) can be generated by visual material, such as a movie containing scenes of urban violence. This effect, obtained in handling humor, was obtained using visual materials by Gilet (2008), in which the methods of humor induction can be made according to culture and necessity to thus achieve its goal with greater precision. The tests tend to easily reach their objectives of humor induction, but the more adapted to a particular population, the better the outcome and effect (Slyker \& McNally, 1991). In Brazil and the other countries where this research was carried out, a need was noted for an adaptation of humor-inducing tests (Gilet 2008). The few edited tests cannot guarantee the same effectiveness in various cultures, but because of the scarcity of such tests, they are still widely used (Bower \& Forgas, 2000).

Unlike induction, data collection has been very reliable over time, with appropriate and adapted tests for each culture. Although the same tools are used, the tests are updated and can be used along with other verification methods, such as positron emission tomography (Davidson, Chapman, Chapman, \& Henriques, 1990). The tests used in the present survey have proven to be effective at reporting and measuring the clear influence of stimulation on concentrated attention and memory. Although not used in this work, other tests are also effective, and other functions can be investigated (e.g., changes in mood and judgment capacity; Thayer, 1996). In addition to deficits reported in these functions, other studies have shown interesting results by researching the positive effects of stimulation, such as with verbal and logical fluency. However, difficulties have been commonly reported in mapping brain activity (Bartolic, 
Basso, Schefft, Glauser, \& Titanic-Schefft, 1999; Sen, 1997, 1998). Reiman et al. (1997) and Lane, Chua and Dolan (1997) also mentioned the difficulty of establishing analyses and mapping of emotions in the brain in regions such as the hypothalamus, prefrontal cortex, thalamus, and median cerebral cortex, which are activated in very similar ways by both adverse and pleasurable stimulation. A prior definition of how much and how certain adverse visual stimulation will interfere with the behavior of an individual is very difficult, but the present findings indicate the clear effects of stimuli and feelings on cognitive performance. The present results suggest that changes in cognitive function, including shortterm memory and concentrated attention, occurred with adverse visual stimulation. Elevated anxiety negatively altered short-term memory and concentrated attention. Future studies should be conducted with a longer period of adverse visual stimulation exposure to evaluate how long these cognitive changes endure and to more precisely determine their effects on cognition and emotion.

\section{References}

Aluja-Fabregat, A., \& Torrubia-Beltri, R. (1998). Viewing of mass media violence, perception of violence, personality and academic achievement. Personality and Individual Differences, 25, 973-989.

Anderson, C.A. (2004). An update on the effects of playing violent video games. Journal of Adolescence, 27, 113-122.

Aronson, E. (1995). The social animal. New York: W.H. Freeman.

Biaggio, A.M.B., \& Natalício, L. (1979/2004). Manual para o Inventário de Ansiedade Traço Estado (IDATE). Rio de Janeiro: CEPA.

Bar-on, M.E., Broughton, D.D., Buttross, S., Corrigan, S., Gedissman, A., Rivas, M.R.G., Rich, M.O., \& Shifrin, D.L. (2001). Media violence. Pediatrics, 108, 1222-1226.

Bartolic, E.I., Basso, M.R., Schefft, B.K., Glauser, T., \& Titanic-Schefft, M. (1999). Effects of experimentally-induced emotional states on frontal lobe cognitive task performance. Neuropsychologia, 37, 677-683.

Bensley, L., \& Van Eenwyk, J. (2001). Video games and real-life aggression: review of the literature. Journal of Adolescent Health, 29, 244-257.

Bower, G.H., \& Forgas, J.P. (2000). Affect, memory, and social cognition. In: E. Eich, G.H. Bower, J.F. Kihlstrom, J.P. Forgas, \& P.M. Miedenthal (Eds.), Cognition and emotion (pp. 87-111). New York: Oxford University Press.

Browne, K.D., \& Hamilton-Giachritsis, C. (2005). The influence of violent media on children and adolescents: a public-health approach. Lancet, 365, 702-710.

Bushman, B.J., \& Cantor, J. (2003). Media ratings for violence and sex: implications for policymakers and parents. American Psychologist, 58, 130-141.

Cambraia, S.V. (1967). Teste atenção concentrada. São Paulo: Vetor.

Cano, A., \& O’Leary, K.D. (2000). Infidelity and separations precipitate major depressive episodes and symptoms of nonspecific depression and anxiety. Journal of Consulting and Clinical Psychology, 68, 774-781.

Cantor, J. (2000). Media violence. Journal of Adolescent Health, 27(2 suppl.), 30-34.

Centerwall, B.S. (1989). Exposure to television as a cause of violence. In G. Comstock (Ed.), Public communication and behavior (pp. 1-58). San Diego: Academic Press.

Compton, R.J. (2003). The interface between emotion and attention: a review of evidence from psychology and neuroscience. Behavioral and Cognitive Neuroscience Reviews, 2, 115-129.

Comstock, G., \& Strasburger, V.C. (1990). Deceptive appearances: television violence and aggressive behavior. Journal of Adolescent Health Care, 11, 31-44.
Cook, D.E., Kestenbaum, C., Honaker, L.M., \& Anderson Jr., E.R. (2000). Joint statement on the impact of entertainment violence on children. Congressional Public Health Summit [http://www.aap. org/advocacy/releases/jstmtevc.htm; accessed: January 11, 2010].

Damasio, A.R. (1999). The feeling of what happens: body and emotion in the making of consciousness. New York: Harcourt Brace.

Davis, M., \& Whalen, P.J. (2001). The amygdala: vigilance and emotion. Molecular Psychiatry, 6, 13-34.

Davidson, R.J., Chapman, J.P., Chapman, L.J., \& Henriques, J.B. (1990). Asymmetrical brain electrical activity discriminates between psychometrically-matched verbal and spatial cognitive tasks. Psychophysiology, 27, 528-543.

Dolan, R.J. (2002). Emotion, cognition and behavior. Science, 298 , 1191-1194.

Freedman, J.L. (1984). Effect of television violence on aggressiveness. Psychological Bulletin, 96, 227-246.

Gable, S., Reis, H.T., \& Elliot, A.J. (2000). Behavioral activation and inhibition in everyday life. Journal of Personality and Social Psychology, 78, 1135-1149.

Gerbner, G. (1988). Violence and terror in the mass media. Paris: United Nations Educational Scientific and Cultural Organization.

Gilet, A.L. (2008). Procédures d'induction d'humeurs en laboratoire: une revue critique. L' Encéphale, 34, 233-239.

Gorsky, E., \& Willis, K. C. (2003). A pilot study examining the relationship between patients' complaints and scores on the Hirschfeld Mood Disorder Questionnaire. Primary Care Companion to The Journal of Clinical Psychiatry, 5, 201-204.

Graeff, F.G. (1999). Ansiedade. In F.G. Graeff, \& M.L. Brandão (Eds.), Neurobiologia das doenças mentais (pp. 109-144). São Paulo: Lemos.

Groebel, J. (1998). Media violence and children. Educational Media International, 35, 216-227.

Gunter, B., \& Furnham, A. (1984). Perceptions of television violence: effects of program genre and type of violence on viewer's judgments of violence portrayals. British Journal of Social Psychology, 23, 155-164.

Gur, R.C., Gunning-Dixon, F., Bilker, W.B., \& Gur, R.E. (2002). Sex differences in temporo-limbic and frontal brain volumes of healthy adults. Cerebral Cortex, 12, 998-1003.

Heilman, K.M. (1997). The neurobiology of emotional experience. Journal of Neuropsychiatry and Clinical Neurosciences, 9, 439-448.

Huesmann, L.R., Moise-Titus, J., Podolski, C.L., \& Eron, L.D. (2003). Longitudinal relations between children's exposure to TV violence and their aggressive and violent behavior in young adulthood: 1977-1992. Developmental Psychology, 39, 201-221.

Katz, L., Fleisher, W., Kjernisted, K., \& Milanese, P. (1996). A review of the psychobiology and pharmacotherapy of posttraumatic stress disorder. Canadian Journal of Psychiatry, 41, 233-238.

Kendler, K.S., Karkowski, L.M., \& Prescott, C.A. (1999). Causal relationship between stressful life events and the onset of major depression. American Journal of Psychiatry, 156, 837-841. King, J.E. (2004).

Kirsh, S.J. (2003). The effects of violent video games on adolescents: the overlooked influence of development. Aggression and Violent Behavior, 8, 377-389.

Labrador, F.J., \& Crespo, M. (1993). Evalución del estrés. In R. Fernandéz-Ballesteros (Ed.), Evaluación conductual hoy: un enfoque para el cambio en psicología clínica y de la salud (pp. 484-529). Madrid: Pirámide.

Lane, R.D., Chua, P.M., Dolan, R.J. (1999). Common effects of emotional valence, arousal and attention on neural activation during visual processing of pictures. Neuropsychologia, 37(9), 989-997.

Leen-Feldner, E.W., Zvolensky, M.J., van Lent, J., Vujanovic, A.A., Bleau, T., Bernstein, A., Bielawski-Branch, A., \& Feldner, M.T. (2007). Anxiety sensitivity moderates tobacco smoking, panic attack symptoms, and bodily complaints in adolescents. Journal of Psychopathology and Behavioral Assessment, 29, 69-79.

Loewenstein, G., \& Lerner, J.S. (2003). The role of affect in decision making. In R.J. Davidson, K.R. Scherer, \& H.H. Goldsmith (Eds.), Handbook of affective sciences (pp. 619-642). Oxford: Oxford University Press.

Margis, R., Picon, P., Cosner, A.F., \& Silveira, R.O. (2003). Relação entre estressores, estresse e ansiedade. Revista de Psiquiatria do Rio Grande do Sul, 25(suppl. 1), 65-74.

McAlister, A. (2000). Juvenile violence in the Americas: innovative studies in research, diagnosis, and prevention. Washington, D.C.: 
Pan American Health Organization.

Nathanson, A.I., \& Cantor, J. (2000). Reducing the aggressionpromoting effect of violent cartoons by increasing children's fictional involvement with the victim: a study of active mediation. Journal Broadcasting and Electronic Media, 44, 125-142.

Rangel, J.G. (2004a). Efeitos e consequências da exposição à violência na televisão. Porto Alegre: Congresso Brasileiro de Ciências das Comunicações.

Rangel, J.G. (2004b). Televisão em foco: a violência e suas relações psicossociais no contexto dos telespectadores. Alceu, 4, 51-64.

Reiman, E.M., Lane, R.D., Ahern, G.L., Schwartz, G.E., Davidson, R.J., Friston, K.J., Yun, L.S., \& Chen, K. (1997). Neuroanatomical correlates of externally and internally generated human emotion. American Journal of Psychiatry, 154, 918-925.

Ribeiro, L., \& Kapczinski, F. (2000). Ansiedade. In F. Kapczinski, J. Quevedo, \& I. Izquierdo (Eds.), Bases biológicas dos transtornos psiquiátricos (pp. 133-141). Porto Alegre: Artmed.

Ritz, T., Alatupa, S., Thöns, M., \& Dahme, B. (2002). Effects of affective picture viewing and imagery on respiratory resistance in nonasthmatic individuals. Psychophysiology, 39, 86-94.

Sargent, J.D., Heatherton, T.F., Ahrens, M.B., Dalton, M.A., Tickle, J.J., \& Beach, M.L. (2002). Adolescent exposure to extremely violent movies. Journal of Adolescent Health, 31, 449-454.

Sarlani, E., \& Greenspan, J.D. (2002). Gender differences in temporal summation of mechanically evoked pain. Pain, 97, 163-169.

Schneider, C. (2000). Safeguarding good scientific practice: new institutional approaches in Germany. Science and Engineering Ethics, 6, 49-56.

Sen, S. (1997). Multiagent systems: milestones and new horizons. Trends in Cognitive Sciences, 1, 334-340.

Sen, S. (1998). Evolution and learning in multiagent systems. International Journal of Human-Computers Studies, 48, 1-7.

Sherry, J.L. (2001). The effects of violent video games on aggression: a meta-analysis. Human Communication Research, 27, 409-431.

Shields, S.A. (2003). Gender in the psychology of emotion: a selective research review. In K.T. Strongman (Ed.), International review of studies on emotion, vol. 1 (pp. 227-245). New York: John Wiley \& Sons.

Silberg, J., Rutter, M., Neale, M., \& Eaves, L. (2001). Genetic moderation of environmental risk for depression and anxiety in adolescent girls. British Journal of Psychiatry, 179, 116-121.

Slyker, J.P., \& McNally, R.J. (1991). Experimental induction of anxious and depressed moods: are Velten and musical procedures necessary? Cognitive Therapy and Research, 15, 33-45.

Sloan, D.M., \& Kornstein, S.G. (2003). Gender differences in depression and response to antidepressant treatment. Psychiatric Clinics of North America, 26, 581-594.

Spielberger, C.D., Gorsuch, R.L., \& Lushene, R.D. (1970). STAI: manual for the State-Trait Anxiety Inventory. Palo Alto, C.A. Consulting Psychologists Press.

Surgeon General's Scientific Advisory Committee on Television and Social Behavior (1972). Television and growing up: the impact of televised violence. Rockville, M.D.: National Institute of Mental Health.

Thayer, R.E. (1996). The origin of everyday moods: managing energy, tension, and stress. New York: Oxford University Press.

Updegraff, J.A., Gable, S.L., \& Taylor, S.E. (2004). What makes experiences satisfying? The interaction of approach-avoidance motivations and emotions in well-being. Journal of Personality and Social Psychology, 86, 496-504.

Vooijs, M.W., \& van der Voort, T.H.A. (1993). Learning about television violence: the impact of a critical viewing curriculum on children's attitudinal judgments of crime series. Journal of Research and Development in Education, 26, 133-142.

Yehuda, R., \& Davidson, J.R.T. (2000). Clinician's manual on posttraumatic stress disorder. London: Science Press.

Zald, D.H., \& Kim, S.W. (2001). The orbitofrontal cortex. In S.P. Salloway, P.F. Malloy, \& J.D. Duffy (Eds.), The frontal lobes and neuropsychiatric illness (pp. 33-70). Washington, D.C.: American Psychiatric Press. 